\title{
GRIT DAN MINDSET PADA MAHASISWA KEPERAWATAN
}

\author{
Grace Fresania Kaparang, Megawati Lestari Gahauna \\ Profesi Ners, Fakultas Keperawatan, Universitas Klabat \\ gracekaparang@unklab.ac.id \\ gahaunamegaL@gmail.com
}

\begin{abstract}
Grit or persistence is an individual effort exerted to achieve a long-term effort with a sustainable spirit and to develop this grittiness, a growth mindset is needed by that individual in order to believe or appreciate these abilities. The purpose of this study was to determine the relationship between grit and mindset among nursing students at Universitas Klabat, using a correlative method and consecutive sampling technique, consented by 226 students. Data analysis employing percentage, frequency, mean, standard deviation, and Spearman's Correlation test. It is found that the grit of the participants averaged in $3.43(S D=0.531)$ signifying that the students were "quite gritty". While for mindset the students were at the "intermediate mindset" level (M= 2.460; $S D=0.676)$. Moreover, Spearman's correlation revealed $p=0.002(<0.01)$ and $r=-0.201$ indicating $a$ negative weak correlation between grit and mindset, signifying that the more gritty the student, the more fixed their mindset. It is recommended to conduct similar research to other students or study program and that the information about grit and mindset could be passed along throughout Universitas Klabat or other schools, and that also experimental study is suggested in the area of grit and mindset. For the institution, it is recommended that grit and mindset seminars, training, or workshops could be conducted for the students that they may aware of their situation and improve to be better and eventually achieve a successful learning experience.
\end{abstract}

Keywords: grit, mindset, nursing students

\begin{abstract}
ABSTRAK
Grit atau ketekunan adalah usaha seseorang untuk mencapai tujuan jangka panjang dengan semangat yang berkelanjutan, dan untuk mengembangkan grit diperlukan growth mindset agar seseorang percaya akan kemampuan diri dan menghargai kemampuan tersebut. Tujuan penelitian ini adalah untuk mengetahui apakah ada hubungan yang signifikan antara grit dan mindset pada mahasiswa Keperawatan Universitas Klabat. Metode penelitian yang digunakan adalah deskriptif korelasi dengan teknik consecutive sampling diikuti oleh 226 mahasiswa yang setuju berpartisipasi. Analisa data menggunakan persentase, frekuensi, serta uji statistik Spearman's Correlation menemukan rata-rata grit dari seluruh partisipan adalah $\mathrm{M}=3.43$ ( $\mathrm{SD}=0.531$ ) yang berarti partisipan berada pada skala "agak gritty". Sedangkan rata-rata mindset dari partisipan berada pada nilai $\mathrm{M}=2.460$ ( $\mathrm{SD}=0.676$ ) yang berarti skala rata-rata "intermediate mindset" dan hasil uji Spearman's correlation menunjukkan nilai $p=0.002(<0.01)$ dengan nilai $r=-0.201$ yang artinya ada hubungan negatif yang signifikan namun lemah antara grit dan mindset pada mahasiswa Keperawatan Universitas Klabat, yang artinya semakin gritty seorang mahasiswa, mereka berada pada mindset yang semakin fixed. Rekomendasi bagi peneliti selanjutnya agar dapat melakukan penelitian dengan menambah jumlah sampel dan memperluas penelitian ke fakultas lain agar informasi mengenai grit dan mindset juga dapat disalurkan kepada semua mahasiswa di Universitas Klabat bahkan di Universitas dan sekolah lain, serta dapat melakukan penelitian eksperimental pada area grit dan mindset. Bagi institusi, kiranya dapat mempelajari grit dan mindset, serta memberikan seminar, training atau workshop mengenai hal ini, sehingga mahasiswa boleh aware mengenai keadaan mereka.
\end{abstract}

Kata kunci: grit, mindset, mahasiswa perawat 


\section{PENDAHULUAN}

Sepanjang sejarah, manusia telah berpendapat bahwa prestasi selalu merupakan produk dari kemampuan intelektual seseorang, oleh karena itu keberhasilan dan kegagalan seseorang berhubungan dengan jumlah kemampuan intelektual yang dimiliki (Sethi \& Shashwati, 2019). Memang, dalam banyak kasus, individu dengan IQ yang lebih rendah atau rata-rata mencapai kualifikasi yang lebih tinggi, memperoleh peran pekerjaan yang lebih berpengaruh dan menerima pendapatan yang lebih tinggi, namun, penelitian mulai menunjukkan kontradiksi tertentu yang mengungkapkan individu dengan IQ yang sama atau lebih rendah secara konsisten mengungguli rekan-rekan mereka yang "lebih cerdas" (Duckworth et al., 2007). Ada pergeseran fokus penelitian terhadap pentingnya sifat dan faktor non-kognitif dalam memprediksi dan mengukur pencapaian dan kesuksesan (Londoner, 1972; Levy \& Dweck, 1998).

Ada minat dalam mengeksplorasi faktorfaktor yang terkait dengan prestasi siswa, dan ada sesuatu yang baru dieksplorasi, grit didefinisikan sebagai kecenderungan seseorang untuk mengejar tujuan jangka panjang dengan ketekunan dan semangat yang berkelanjutan, dan grit memainkan peran penting dalam prestasi siswa (Wang, et al., 2017). Anak-anak mungkin memiliki keyakinan yang salah dan memiliki kesalahpahaman tentang pengembangan keterampilan keyakinan yang menghalangi kemampuan dalam menunjukkan kinerja. Ketika siswa berjuang dengan tugas, mereka mungkin percaya bahwa mereka tidak memiliki kemampuan untuk menyelesaikan masalah, dan oleh karena itu akhirnya menyerah. Penting bagi siswa untuk memahami bahwa boleh saja merasa bingung ketika mempelajari sesuatu yang baru, dan sebenarnya, itu diharapkan (Bashant, 2014).

Ciri-ciri kognitif dalam bidang ini diisi oleh Angela Duckworth, yang terutama memusatkan perhatian pada konsep grit. Grit telah diposisikan sebagai sesuatu yang sangat berpengaruh terkait dengan keberhasilan dan prestasi akademik. Telah ditemukan bahwa grit dikaitkan dengan produktivitas akademik dan keterlibatan (Hodge et al., 2017); motivasi akademik (Eskreis-Winkler et al., 2014); prestasi akademik (Pate et al., 2017); tugas yang menantang (Lucas et al., 2015); kinerja akademik (Kelly et al., 2014); jumlah jam belajar (Cross, 2014); strategi pembelajaran (Weisskirch, 2016); nilai tugas dan orientasi tujuan (Muenks et al., 2016, 2017); pengejaran dan pencapaian pelatihan pascasarjana (Palisoc et al., 2017), dan retensi siswa (Crede et al., 2016). Sekali lagi ada juga penelitian yang menunjukkan bahwa grit bukan merupakan prediktor pencapaian dan kinerja akademik (Ivcevic dan Brackett, 2014; Bazelais et al., 2016; Muenks et al., 2016; Palisoc et al., 2017). Selain konstruksi grit yang dikaitkan dengan hasil akademik, beberapa penelitian telah menunjukkan hubungan antara grit dan hasil pribadi tertentu. Grit memiliki hubungan yang signifikan dengan pencapaian kehidupan yang lebih tinggi (Abuhassàn \& Bates, 2015); peningkatan pencapaian tujuan (Sheldon et al., 2015); diagnosis gangguan kejiwaan yang terjadi bersamaan (Griffin et al., 2016); status pekerjaan (Griffin et al., 2016); terbakar (Halliday et $a l .$, 2016) dan keterampilan manajemen perawatan kesehatan yang lebih besar (Sharkey et al., 2017). Telah ditunjukkan juga dalam beberapa penelitian bahwa bahwa grit berkorelasi positif dengan growth mindset (mindset berkembang) (Duckworth et al., 2007; Hochanadel \& Finamore, 2015); kesehatan mental yang lebih tinggi (Sharkey et al., 2017); dan stabilitas emosional selama peristiwa kehidupan yang penuh tekanan atau negatif (Blalock et al., 2015).

Mindset adalah keyakinan yang mengarahkan cara kita menangani situasi, cara kita memilah apa yang sedang terjadi dan apa yang harus kita lakukan. Mindset kita membantu kita menemukan peluang, tetapi mereka juga bisa menjebak kita dalam siklus yang mengalahkan diri sendiri (Klein, 2016). Dweck (2009) dalam penelitiannya telah mengidentifikasi dua jenis mindset yang dapat dimiliki seseorang mengenai bakat dan kemampuannya yaitu fixed mindset (mindset tetap) dan growth mindset (mindset berkembang). Menurut Dweck (2010), mereka yang mungkin memiliki fixedmindset percaya bahwa kecerdasan adalah sifat statis: ada siswa cerdas dan ada yang tidak, hanya itu. Yang memilikigrowthmindset percaya bahwa kecerdasan dapat dikembangkan dengan berbagai cara misalnya, melalui upaya dan instruksi. Growth mindset tidak menyiratkan bahwa setiap orang adalah sama atau bahwa siapa pun bisa menjadi Einstein, tetapi itu menyiratkan bahwa kemampuan intelektual setiap orang dapat tumbuh dan bahwa bahkan Einstein sebelum melakukan upaya tanpa henti bertahun-tahun dengan penuh semangat. Mereka yang berpikir kecerdasan itu tidak dapat diubah, mengerahkan sedikit usaha untuk berhasil itu memiliki fixed mindset (kapasitas permanen) sedangkan yang memiliki growth mindset adalah 
yang tahu bahwa kecerdasan dapat berkembang. Growth mindset ini dianggap sebagai soft skill dan dapat diajarkan ke fakultas, siswa dan orang tua. Duckworth dan Dweck berkolaborasi, melakukan penelitian untuk menentukan bagaimana keyakinan bahwa kegagalan itu permanen dapat mencegah siswa dari keberhasilan akademik. Duckworth menyimpulkan bahwa memiliki growth mindset dapat mengembangkan grit. Mengidentifikasi gaya penjelas dengan menggunakan penilaian grit adalah salah satu cara untuk menentukan dimana siswa dapat berupaya untuk belajar bertahan dalam menghadapi tantangan akademik. Fakultas seharusnya tidak fokus pada membuat nilai bagus, tetapi bagaimana menantang orang itu dan mengajar mereka untuk menciptakan solusi. Selain itu, mengajarkan growth mindset dan grit untuk memfasilitasi tujuan jangka panjang dan cara mencapainya (Hochanadel \& Finamore, 2015).

Mahasiswa yang berumur 18 hingga 25 tahun berada pada tahap perkembangan dewasa awal dan memiliki tugas perkembangan yang perlu dicapai dan dipersiapkan, seperti memegang tanggung jawab sebagai bagian dari masyarakat, mulai bekerja mencari pemasukan, serta menemukan kelompok sosial yang sesuai dengan diri (Hurlock, 2009). Dalam studi yang dilakukan oleh Limeri, et al. (2020) pada kelompok mahasiswa, ditemukan bahwa mahasiswa yang semakin bergumul dalam matakuliah yang menantang akan semakin mengembangkan mindset yang fixed. Jika dilihat dari pengalaman di berbagai Universitas sekarang ini, apalagi dalam Fakultas Keperawatan, matakuliah dan praktik di Rumah Sakit merupakan tantangan harian bagi mahasiswa.

Grit dan Mindset adalah istilah yang belum terlalu dikenal di Indonesia dan khususnya di Universitas Klabat. Berdasarkan hasil observasi peneliti pada mahasiswa keperawatan yang sedang aktif berkuliah di Universitas Klabat, didapati banyak mahasiwa yang cenderung gampang menyerah dan pasrah akan keadaan atau situasi yang sedang dialami. Oleh karena itu semua mahasiswa memerlukan ketekunan atau grit untuk mengatasi permasalahan yang sedang dialami.

Berdasarkan penjelasan dilatar belakang terkait pentingnya grit untuk mengembangkan bahkan mempertahankan mindset yang dimiliki oleh masing-masing mahasiswa, oleh karena itu peneliti tertarik melakukan penelitian yang berjudul "Grit dan Mindset pada Mahasiswa Keperawatan" dengan tujuan untuk mencari tahu bagaimanakah gambaran grit pada mahasiswa keperawatan, bagaimanakah gambaran mindset pada mahasiswa keperawatan, serta mengetahui apakah ada hubungan antara grit dan mindset pada mahasiswa keperawatan. Hasil penelitian ini diharapkan dapat menjadi data dasar mengenai tingkat grit dan mindset mahasiswa, sehingga dapat ditindaklanjuti oleh administrator fakultas untuk menjadi masukan dalam perbaikan sistem pendidikan mahasiswa yang akan mempersiapkan pemimpin-pemimpin masa depan yang tidak mudah menyerah dalam melakukan yang terbaik, dan memiliki pribadi yang terbuka untuk selalu belajar dan mengembangkan diri.

\section{MATERI DAN METODE}

Penelitian ini menggunakan metode korelasi yang bertujuan untuk mengkaji hubungan antara dua variabel dan dapat dilanjutkan untuk membuat prediksi (Stangor, 2011). Variabel dalam penelitian ini adalah grit sebagai variabel independen dan variabel dependennya adalah mindset. Instrumen yang digunakan untuk mengukur grit adalah terjemahan Bahasa Indonesia 12-Items Grit Scale yang dikembangkan oleh Duckworth, et al. (2007) yang terdiri dari 12 pernyataan dan skor maksimum 5 (sangat tekun) dan skor paling rendah 1 (sangat tidak tekun). Selanjutnya, instrumen untuk mengukur mindset terjemahan dari Bahasa Indonesia Mindset Quiz. yang dikembangkan oleh Dweck (1999) yang terdiri dari 3 pernyataan, dengan penetapan interval menurut rumus cut-off point sederhana (Balkishan \& Ravikant, 2014) yaitu 1-2.3 adalah kategori fixed mindset, interval 2.3-3.7 kategori intermediate mindset, dan interval 3.7-5 kategori growth mindset. Untuk mengidentifikasi hubungan antara grit dan mindset digunakan rumus statistik Spearman's Correlation.

Teknik sampling yang digunakan dalam penelitian ini adalah consecutive sampling yaitu sampel dipilih sampai memenuhi jumlah yang ditentukan (Martínez-Mesa, et al., 2016). Partisipan dalam penelitian ini adalah semua mahasiswa Fakultas Keperawatan Universitas Klabat, Airmadidi, Sulawesi Utara yang bersedia menjadi responden dengan menandatangani Informed Consent. Jumlah populasi mahasiswa keperawatan Universitas Klabat berjumlah 544 orang, kemudian peneliti melakukan pemotongan sampel dengan rumus Slovin, dan hasil pemotongan sampel 226 orang sebagai jumlah minimum partisipan.

Alur pengumpulan data dalam penelitian ini dimulai penentuan rencana penelitian dan 
menyiapkan materi. Setelah mendapatkan persetujuan penelitian dari Fakultas Keperawatan dengan nomor surat 022/UK/FKEP.SPM/II/2020 maka dilaksanakan pengumpulan data pada 19 Februari - 13 Maret 2020 yang diawali dengan menjelaskan maksud dan tujuan pembuatan penelitian, berapa lama penelitian yang akan dilakukan, kerahasiaan data yang akan diambil yang tertera dalam informed consent, setelah mendapat persetujuan dari responden kemudian akan dilakukan pengolahan data melalui SPSS.

\section{HASIL}

Gambaran grit dari 226 partisipan nilai $\mathrm{M}=3.43$ yang berarti terdapat pada skala "agak gritty" ( $\mathrm{SD}=0.531$ ). Spesifiknya, $54.42 \%$ partisipan $(\mathrm{n}=123)$ teridentifikasi dalam kategori "agak gritty" diikuti oleh $43.81 \%$ partisipan $(n=99)$ teridentifikasi dalam kategori "gritty", $1.33 \%$ partisipan $(n=3)$ teridentifikasi "kurang gritty", dan $0.44 \%$ partisipan $(\mathrm{n}=1)$ teridentifikasi "sangat gritty". Tabel 1 merangkumkan gambaran grit.

Tabel 1.Gambaran grit mahasiswa keperawatan $(\mathrm{n}=226)$

\begin{tabular}{lcccc}
\hline Grit & $\mathrm{f}$ & $\%$ & $\mathrm{M}$ & $\mathrm{SD}$ \\
\hline Keseluruhan & 226 & 100 & 3.43 & .531 \\
Tidak "gritty" & 0 & 0 & & \\
Kurang "gritty" & 3 & 1.33 & & \\
Agak "gritty" & 123 & 54.42 & & \\
Gritty & 99 & 43.81 & & \\
Sangat "gritty" & 1 & 0.44 & & \\
\hline Catatan: f=frekuensi; & $\%=$ persentase; & M=rata-rata; \\
SD=standar deviasi & & &
\end{tabular}

Selanjutnya berdasarkan tabel 2 dapat dilihat gambaran mindset 226 partisipan didapati nilai $\mathrm{M}=2.460$ yang berarti skala rata-rata adalah pada skala "intermediate mindset" $(\mathrm{SD}=0.676)$. Spesifiknya, $65.04 \%$ partisipan $(\mathrm{n}=147)$ teridentifikasi dalam kategori "intermediate mindset", diikuti oleh $34.07 \%$ partisipan $(\mathrm{n}=77)$ teridentifikasi dalam kategori "fixed mindset", dan $0.89 \%$ partisipan $(\mathrm{n}=2)$ teridentifikasi dalam kategori "growth mindset".
Tabel 2.Gambaran mindset mahasiswa keperawatan $(\mathrm{n}=226)$

\begin{tabular}{lcccc}
\multicolumn{1}{c}{ Mindset } & $\mathrm{n}$ & $\%$ & $\mathrm{M}$ & $\mathrm{SD}$ \\
\hline Keseluruhan & 226 & 100 & 2.460 & 0.676 \\
Fixed Mindset & 77 & 34.07 & & \\
Intermediate Mindset & 147 & 65.04 & & \\
Growth Mindset & 2 & 0.89 & & \\
\hline Catatan: f=frekuensi; & $\%=$ persentase; & M= rata-rata; \\
SD=standar deviasi & & & &
\end{tabular}

Hasil uji Spearman's correlation menunjukkan hubungan antara grit dan mindset dengan nilai $p=0.002(<0.01)$ dengan nilai $r=-$ 0.201 yang artinya ada hubungan negatif yang signifikan namun lemah antara grit dan mindset pada mahasiswa Keperawatan Universitas Klabat.

Tabel 3. Hubungan grit dan mindset pada mahasiswa keperawatan

\begin{tabular}{lll}
\hline $\begin{array}{l}\text { Spearman's } \\
\text { rho }\end{array}$ & Mindset & \\
\hline Grit & $\begin{array}{l}\text { Correlation } \\
\text { coefficient }\end{array}$ & $-.201^{* *}$ \\
& Sig. (2-tailed) & .002 \\
\hline
\end{tabular}

\section{PEMBAHASAN}

Hasil gambaran grit pada mahasiswa Keperawaran Universitas Klabat, meyatakan bahwa mayoritas partisipan berada pada tingkat "agak gritty".Sistem pendidikan di Indonesia memang cenderung mementingkan kecerdasan intelektual dan metode pembelajaran hafalan seseorang, bahkan apabila seseorang mempunyai kecerdasan intelektual yang mumpuni sehingga dapat dengan mudah masuk atau memilih perguruan tinggi, sedangkan siswa dengan kecerdasan itelektual yang kurang baik sering mengalami kesulitan akan hal ini, penting bagi setiap orang terutama tenaga pendidik mengetahui tentang grit (ketekunan) sehingga dapat memotivasi siswa untuk tau bahwa kecerdasan dapat dikembangkan (Tabrani, 2017). Ada banyak penelitian yang menunjukkan bahwa kemampuan seperti bakat, kecerdasan, dan IQ bukanlah prediktor signifikan dari pencapaian tinggi atau keberhasilan di kemudian hari (De Vera, Gavino, \& Portugal, 2015; Duckworth et al., 2007; Duckworth \& Seligman, 2005; Dweck, 2007). Penelitian saat ini menyatakan bahwa grit seperti sifat terkait dengan kinerja yang lebih baik dan keberhasilan yang lebih besar di kedua akademik dan di dunia nyata (De Vera et al., 2015; Duckworth et al. 2007; Ivcevic \& 
Brackett, 2014). Jika siswa dengan kemampuan akademik yang lebih rendah dapat memiliki kinerja yang sama baiknya dibandingkan dengan siswa dengan kemampuan akademik yang lebih tinggi maka mungkin ada ukuran prestasi akademik atau kegigihan yang lebih dapat diandalkan di perguruan tinggi. Grit adalah ketekunan dan gairah yang diperlukan untuk mencapai tujuan jangka panjang dan memerlukan kerja keras sebagai alat untuk menghadapi tantangan serta mempertahankan usaha dan minat dalam jangka panjang atau bertahuntahun terlepas dari kegagalan, kesulitan dan kemunduran yang dialami seseorang (Duckworth, Peterson, Matthews, \& Kelly, 2007).

Asumsi bahwa mayoritas partisipan ada pada skala "agak gritty" berdasarkan hasil observasi pada beberapa mahasiswa, didapatkan hasil bahwa karena banyaknya tugas, padatnya jadwal kuliah serta batas waktu pemasukan tugas, mahasiswa tidak terlalu menekuni beberapa mata kuliah, asalkan tugas tersebut selesai dan dikumpulkan tepat waktu, ada juga yang kurang bersemangat karena paksaan/pilihan orang tua untuk berkuliah di jurusan Keperawatan. Hal ini juga bisa dipengaruhi oleh kurangnya waktu untuk mengasah kemempuan serta mahasiswa belum menemukan apa yang menjadi ketertarikannya, mungkin belum menentukan tujuan serta kurangnya harapan akan masa depan. Oleh karena itu perlu ditanamkan konsep menurut Angela Lee Duckworth yaitu: "Grit is sticking with your future, day in, day out, not just for the week, not just for the month, but for years, and working really hard to make that future a reality. Grit is living life like it's a marathon, not a sprint. Grit dalam pendidikan adalah bagaimana seseorang dapat mencapai tujuan jangka panjang dengan mengatasi hambatan dan tantangan (Hochanadel \& Finamore, 2015).

Lebih lanjut dari hasil gambaran mindset pada mahasiswa Keperawatan Universitas Klabat menyatakan bahwa mayoritas partisipan berada pada tingkat "intermediate mindset". Berdasarkan hasil observasi, ditemukan bahwa dari segi disiplin dan peraturan di UNKLAB kebanyakan dari mahasiswa merasa tertekan sehingga mereka lebih memilih untuk memenuhi segala tuntutan dengan kemampuan yang apa adanya tanpa ingin mengembangkan potensi untuk membuat tuntutan pendidikan lebih bagus lagi atau mengembangkan kemampuan mereka untuk menyelesaikan tututan perkuliahan.

Selanjutnya teman sebaya juga dapat mempengaruhi mindset mahasiswa karena mahasiwa merasa bahwa ada ikatan persahabatan atau kesetiaan pada teman sehingga mahasiswa cenderung menunda-nunda suatu pekerjaan atau menjadi apa adanya agar bisa tetap sejalan atau tetap bisa maju bersama teman tanpa ada yang tertinggal. Selain itu diri sendiri juga yang cenderung pasrah akan keadaan yang dialami oleh mahasiswa itu sendri, mereka berpikir bahwa tidak perlu membuat tugas dengan sangat baik yang terpenting adalah mengumpulkan tugas tepat waktu dan lulus mata kuliah yang diambil atau sama dengan pemikiran ketika masih di sekolah menengah bahwa tidak perlu nilai yang bagus yang terpenting adalah naik kelas, hal ini membuat kebanyakan mahasiswa tidak menyadari potensi-potensi yang sebenarnya bisa dikembangkan untuk mendapatkan hasil yang baik dari pendidikan akademik.

Maulana, Saveinus, Nurul dan Achmad (2019) sistem pendidikan di Indonesia terlihat begitu kental dengan ranking persaingan dan tidak naik kelas, juga dapat mempengaruhi mindset mahasiswa atau pun siswa yang ada di Indonesia. Siswa dituntut untuk mengejar rangking dan naik kelas atau lulus mata kuliah, kenyataan ini tampak tidak sejalan dengan pendapat Dweck (2010) yang menyatakan bahwa siswa yang berprestasi lebih baik berada disekolah bersama dengan guru yang percaya bahwa kecerdasan tidaklah tetap tapi dapat dikembangkan, mengajarkan siswa bahwa kecerdasan seseorang dapat "tumbuh" sangat kuat. Oleh karena itu perlu peran penting dari tenaga pendidikan untuk menerapkan hal ini guna memotivasi siswa untuk mengerjakan perkerjaan menantang, karena growth mindset berfokus pada upaya seseorang. Menurut Kench, Huzelhurst dan Otulaja (2016) seseorang tidak menyerah ketika menemukan kesalahan dan terus mengembangkan strategi pemecahan masalah untuk memperbaiki kesalahan. Tenggang waktu yang diberikan berfungsi untuk mengembangkan motivasi seseorang untuk tetap fokus dengan tujuannya. Growth mindset mengubah pemikiran seseorang bahwa tingkat kecerdasan bukan angka yang tetap dan dapat berubah. Growth mindset ditujukan untuk membantu seseorang untuk menutupi kesenjangan bukan untuk menyembunyikan kesenjangan tersebut. Jika "melarang" fixed mindset, maka kemungkinan akan menciptakan growth mindset yang kurang tepat atau bahkan salah. Namun jika memperhatikan dengan cermat apa yang pemicu mindset maka seseorang dapat memulai perjalanan yang benar menuju growth mindset (Dweck, 2015).

Hasil hubungan antara grit dan mindset ada hubungan yang signifikan namun lemah antara grit 
dan mindset dengan arah hubungan negatif. Apabila grit dan mindset diinformasikan atau di sosialisasikan kepada mahasiswa Keperawatan Universitas Klabat dan diberikan waktu untuk menumbuhkan grit dan mindset dengan bantuan atau motivasi dari tenaga pengajar maka sesuai dengan pembuktian Duckworth (2007) bahwa grit dapat membantu mencapai tujuan jangka panjang serta Dweck (2015) yakni ketika kita memperhatikan dengan cermat apa yang memicu mindset maka seseorang dapat memulai perjalanan yang benar menuju growth mindset, maka bukan hal yang tidak mungkin grit dan mindset mahasiswa Keperawatan Universitas Klabat dapat mencapai skala "gritty" dan growth mindset. Dalam studi yang dilakukan oleh Limeri, et al. (2020) pada kelompok mahasiswa, ditemukan bahwa mahasiswa yang semakin bergumul dalam matakuliah yang menantang akan semakin mengembangkan mindset yang fixed dan jika dilihat dari pengalaman di berbagai Universitas Klabat sekarang ini, apalagi dalam Fakultas Keperawatan, matakuliah dan praktik di Rumah Sakit merupakan tantangan harian bagi mahasiswa. Namun, pengetahuan struktural mengenai dasar pemikiran grit ini seharusnya tidak menyurutkan gagasan bahwa grit adalah konstruksi yang dapat dikembangkan dan dibangun. Memang, growth mindset telah sangat terkait dengan adanya grit pada individu (Hochanadel \& Finamore, 2015) dan lingkungan akademik yang mendorong

\section{REFERENSI}

Abuhassan, A., Bates, T. C. (2015). Grit: distinguishing effortful persistence from conscientiousness. Journal of Individual Differences.36(4).doi: $\quad 10.1027 / 1614-$ 0001/a000175

Balkishan, S. \& Ravikant, J. (2014). Right Choice Of A Method For Determination Of Cut-Off Values: A Statistical Too For A Diagnostic Test. Asian Journal Of Medical Sciences. 5.30-34. 10.3126/ajms.v5i3.9296

Bashant, J. (2014). Developing grit in our students: why grit is such a desirable traits, and practical strategies for teacher and school. Journal for Leadership and Instruction, Diakses pertumbuhan cenderung mendorong siswa belajar untuk bertahan melalui tantangan (Duckworth et al., 2007 ; Hochanadel \& Finamore, 2015).

\section{SIMPULAN DAN SARAN}

Berdasarkan hasil penelitian yang telah dilakukan dapat disimpulkan, bahwa gambaran grit mahasiswa Keperawatan Universitas Klabat ratarata berada pada kategori "agak gritty", sedangkan gambaran mindset pada mahasiswa Keperawatan Universitas Klabat berada pada kategori "intermediate mindset". Selanjutnya grit dan mindset mahasiswa Keperawatan Universitas Klabat memiliki hubungan yang signifikan namun lemah dengan arah hubungan negatifyang artinya semakin gritty seorang mahasiswa, mereka berada pada mindset yang semakin fixed.

Bagi peneliti selanjutnya agar dapat melakukan penelitian dengan menambah jumlah sample dan memperluas penelitian ke fakultas lain agar informasi mengenai grit dan mindset juga dapat disalurkan kepada semua mahasiswa di Universitas Klabat bahkan di Universitas dan sekolah lain, serta dapat melakukan penelitian eksperimental pada area grit dan mindset.

Bagi institusi, kiranya dapat mempelajari grit dan mindset, serta memberikan seminar, training atau workshop mengenai hal ini, sehingga mahasiswa boleh aware mengenai keadaan mereka.

https://files.eric.ed.gov/fulltext/EJ1081394. pdf

Bazelias, P., Lemay, D. J., Doleck, T. (2016). How does grit impact college students' academic achievement in science?. European Journal of Science and Mathematics Education. 4(1). Diakses dari: https://files.eric.ed.gov/fulltext/EJ1107756. pdf

Crede, M., Tynan, M. C., Harms, P. D. (2016). Much ado about grit: a meta-analytic synthesis of the grit literature. Journal of Personality and Social Psychology. 113(3). doi: 10.1037/pspp000010

Cross, T. M. (2014). The gritty: grit and nontraditional doctoral student success. Journal 
of Education. 11(3). Diakses dari: https://www.thejeo.com/archive/2014_11_ $3 /$ cross

Duckworth, A. L., Peterson, C., Matthews, M. D., \& Kelly. D. R. (2007). Grit: perseverance and passion for long-term goals. Journal of Personality and Social Psychology. 92(6). 1087-1101. doi: 10.1037/00223514.92.6.108

Dweck, C. S. (2009). Mindsets: developing talent through a growth mindset. Artikel: Olympic Coach. Diakes dari: https://www.teamusa.org/Hmedia/USA_Vol leyball/Documents/Resource/OlympCoach Mag_Win\%2009_Vol\%2021_Mindset_car ol\%Dweck.pdf

Dweck, C. S. (2010). Mind-sets and equitable education. Article: Principal Leadership. Diakses dari: https://eschs.weebly.com/uploads/2/5/1/7/2 5174886/mind-sets-and-equitableeducation.pdf

Dweck, C. S. (2015). Education Week: Carol Dweck revisits the growth mindset. Diakses dari: https://www.edweek.org/ew/articles/2015/0 9/23/carol-dweck-revisits-the-growthmindset.html

Eskreis-Winkler, L., Shulman, E. P., Beal, S. A., Duckworth, A. L. (2014). The grit effect: predicting retention in the military, the workplace, school and marriage. Frontiers in Phsychology. 5(36). doi: https://doi.org/10.3389/fpsyg.2014.00036

Griffin, M. L., McDermott, K. A., McHugh, R. K., Fitzmaurice, G. M., Weiss, R. D. (2016). Grit in patients with substance use disorders. Am J Addict. 25(8). doi:10.1111/ajad.12460

Halliday, L., Walker, A., Vig, S., Hines, J., Brecknell, J. (2016). Grit and burnout in UK doctors: a cross-sectional study across specialties and stages of training. $B M J$ Journal. 93(1101). doi: 10.1136/postgradmedj-2015-133919

Hochanadel, A., Finamore, D. (2015). Fixed and growth mindset in education and how grit helps students persist in the face of adversity. Journal of International Education Research. 11(1). 47-50. doi: 10.19030/jier.v11i1.9099

Hodge, B., Wright, B., Bennett, P. (2017). The role of grit in determining engagement and academic outcomes for university students. Research in Higher Education. doi: 10.1007/s11162-017-9474-y

Hurloch, E. B. (2009). Psikologi perkembangan: suatu pendekatan sepanjang rentang kehidupan. Jakarta: Erlangga

Isnaeni, M. (2019). Pengaruh growth mindset terhadap grit akademik pada mahasiswa yang mengikuti organisasi. Skripsi: Jurusan Psikologi Fakultas Ilmu Pendidikan Universitas Negeri Semarang. Diakses dari: https://lib.unnes.ac.id/33657/1/1511415029 _Optimized.pdf

Ivcevic, Z., Brackett, M. (2014). Predicting school success: compairing conscientiousness, grit, and emotion regulation ability. Journal of Research in Personality. 52. doi: 10.1016/j.jrp.2014.06.005

Kannangara, C. S. et all. (2018). All that glitters is not grit: three studies of grit in university students. Article: University of Bolton, Bolton, United Kingdom. doi: 10.3389/fpsyg.2018.01539

Kelly, D. R., Matthews, M. D., Bartone, P. T. (2014). Grit and hardiness as predictors of performance among west point cadets. Military Psychology. 26(4). doi: http://dx.doi.org/10.1037/mil0000050

Kench, D., Hezelhurst, S., Otulaja, F. (2016). Grit and growth mindset among high school students in a computer programming project: a mixed methods study. Paper: University of Witwatersrand. Diakses dari: https://www.researchgate.net/profile/Femi_ Otulaja/publication/309172702_Grit_and_ Growth_Mindset_Among_High_School_St udents_in_a_Computer_Programming_Proj ect_A_Mixed_Methods_Study/links/5ae5d bd0aca272ba5080e860/Grit-and-GrowthMindset-Among-High-School-Students-in- 
a-Computer-Programming-Project-A-

Mixed-Methods-

Study.pdf?origin=publication_detail

Klein, G. (2016). Psychology today: mindsets: what they are and why they matter. Diakses dari: https://www.psychologytoday.com/us/blog/ seeing-what-others-dont/201605/mindsets

Levy, S. R., Dweck, C. S. (1998). Trait-versus process-focused social judgment. Social Cognition. 16(1). Diakses dari: https://guilfordjournals.com/doi/pdfplus/10 $.1521 /$ soco.1998.16.1.151

Limeri, L. B., Carter, N. T., Choe, J., Harper, H. G., Martin, H. R., Benton, A., \& Dolan, E. L. (2020). Growing a growth mindset:

Characterizing how and why undergraduate students' mindsets change. International Journal of STEM Education, 7(1). doi:10.1186/s40594-020-00227-2

Londoner, C. A. (1972). Perseverance versus nonperseverance patterns among adult high school students. Adult Education. 22(3). doi: 10.1177/074171367202200301

Lucas, G. M., Gratch, J., Cheng, L., Marsella, S. (2015). When the going gets tough: grit predicts costly perseverance. Journal of Research in Personality. 59. doi: 10.1016/j.jrp.2015.08.004

Martínez-Mesa, J., González-Chica, D. A., Duquia, R. P., Bonamigo, R. R., \& Bastos, J. L. (2016). Sampling: how to select participants in my research study?. Anais brasileiros de dermatologia, 91(3), 326-330. https://doi.org/10.1590/abd18064841.20165254

Maulana, A. A., Saverinus, G., Nurul, U., \& Achmad, S. (2019). Analisis komparasi sistem pendidikan Indonesia dan Finlandia. Jurnal Studi Manajemen Pendidikan. 3(2). doi:

http://dx.doi.org/10.29240/jsmp.v3i2.1102

Muenks, K., Wigfield, A., Yang, J. S., O’Neal, C. R. (2016). How tru is grit? Assessing its relations to high school and college students' personality characteristics, self- regulation, engagement, and achievement. Journal of Educational Psychology. 109(5). doi: https://doi.prg/10.1037/edu0000153

Palisoc, A. J. L. et all. (2017). Relationship between grit with academic performance and attainment of postgraduate training in pharmacy students. Am J Pharm Educ. 81(4). doi: 10.5688/ajpe81467

Pate, A. N. et all. (2017). Measurement of grit and correlation to student pharmacist academic performance. Am J Pharm Educ. 81(6). doi: 10.5688/ajpe816105

Sethi, D., Shashwati, S. (2019). Say no to setback: grit \& growth mindset have got yourback. International Journal of Innovative Studies in Sochiology and Humanities. 4(3). 18-26. Diakses dari: https://www.academia.edu/38557375/Say_ No_to_Setbacks_Grit_and_Growth_Minds et_Have_Got_Your_Back

Sharkey, C. M. et all. (2017). The role of grit in college student health care management skills and health-related quality of life. $J$ Pediatr Psychol. 42(9). doi: 10.1093/jpepsy/jsx073

Sheldon, K. M., Jose, P. E., Kashdan, T. B., Jarden, A. (2015). Personality, effective goalstriving, and enhanced well-being: comparing 10 candidate personality strengths. Pers Soc Psychol Bull. 41(4). doi: 10.1177/0146167215573211

Stangor, C. (2011). Research methods for the behavioral sciences (4th ed.). Mountain View, CA: Cengage. Diakses dari: http://www.opentextbooks.org.hk/ditatopic $/ 26400$

Tabrani, Z. A. (2017). Sistem pendidikan di Indonesia: antara solusi dan ilusi. Artikel. doi: 10.13140/RG.2.2.21465.62569

Wang. et all. (2017). Neuroanatomical correlates of grit: growth mindset mediates the association between gray matter structure and trait grit in late adolescene. Article: National University of Defense Technology. doi: 10.1002/hbm.23944 
Weisskirch, R. S. (2016). Grit, self-esteem, learning strategies and attitudes and estimated and achieved course grades among college students. Current Psychology. $37 . \quad$ doi: https://doi.org/10.1007/s12144-0169485-4 